\title{
Assessment of children born to mothers who are renal allograft recipients
}

\author{
U G Thakkar ${ }^{1}$, V V Mishra ${ }^{2}$, AV Vanikar ${ }^{3}$, H V Patel ${ }^{4}$, R S Agrawal ${ }^{2}$, VR Shah ${ }^{5}$, H L Trivedi ${ }^{4}$
}

Sri Lanka Journal of Child Health, 2014; 43(1): 27-32

\begin{abstract}
Objective: To assess the neonatal, current physical status, renal and developmental assessment of children born to renal allograft recipients (RAR) and to assess the psychological impact of successful childbirth on RAR and their families.
\end{abstract}

Method: A cross-sectional prevalence survey of children born to female RAR was performed. Data of newborn and mothers were collected using hospital records and parental questionnaire. Infants were subjected to physical examination, developmental assessment, urinalysis and ultrasound. Psychological impact on mothers and families was recorded.

Results: Four children born to 4 female RAR formed the study group. Two RAR had history of abortions. All RAR underwent lower segment caesarean sections. Two children were preterm and 2 were small for gestational age. Mean current age of infants was 13.3 months and mean birth weight was $2052.5 \mathrm{~g}$. General health, physical assessment and development were unremarkable in all. All mothers were apprehensive of renal disease in their children despite normal renal function. No congenital anomalies were noted. There was no maternal or neonatal mortality. Mothers and families were happy and fulfilled with childbirth.

${ }^{1}$ Department of Regenerative Medicine and Paediatrics, ${ }^{2}$ Department of Obstetrics and Gynaecology, ${ }^{3}$ Department of Pathology, Laboratory Medicine, Transfusion Services and Immunohaematology, ${ }^{4}$ Department of Nephrology and Transplantation Medicine, ${ }^{5}$ Department of Anaesthesiology and Critical Care, $G R$ Doshi and KM Mehta Institute of Kidney Diseases \& Research Centre, Dr. HL Trivedi Institute of Transplantation Sciences, Gujarat, India

(Received on 18 June 2013: Accepted after revision on 26 July 2013)
Conclusions: Childbirth in RAR with stable graft function improves social quality of life of families. Post-natal progress is not adversely influenced by immunosuppression of RAR. However, preterm-delivery and intrauterine growth retardation remain risk factors.

(Key words: Renal transplant; renal allograft recipient; pregnancy; newborn; preterm delivery; intra uterine growth retardation)

\section{Introduction}

The first successful pregnancy in a female following renal transplantation (RT) was reported in $1963^{1}$. Relatively little data is available regarding the outcome of pregnancies from female renal allograft recipients (RAR) ${ }^{1}$. For a woman with a functioning renal allograft to have a successful pregnancy is the best possible proof of rehabilitation from end stage renal disease (ESRD). Pregnancies in female RAR are considered as high risk and managed in tertiary care centres having a team of nephrologists, obstetricians and neonatologists to avoid unnecessary complications.

\section{Objective}

This study was undertaken to assess the neonatal, current physical status, renal and developmental assessment of children born to mothers who are RAR and to assess the psychological impact of successful childbirth on RAR and their families.

\section{Method}

A retrospective single centre cross-sectional prevalence survey carried out from January 2007 to January 2013 identified a total of 5 post renal transplant females of child bearing age who became pregnant. These female RAR and their children were assessed. Details of medication taken at the time of conception and throughout pregnancy, birth history and full paediatric history of children were gathered from parents 
using a semi-structured interview and questionnaire and confirmed using their posttransplant case records. Physical examination of the children including standard mercury sphygmomanometry was performed. The developmental assessment included child's gross motor, fine motor, adaptive, language, personal, social development and scholastic achievements. A single urine sample was collected for routine urinalysis as well as for microscopy and if required bacteriological examination. Ultrasound (US) examination of the child's abdomen including urinary tract was performed by one ultra-sonographer. The study was approved by the Institution Review Board. Informed consent was obtained from all participants. In the younger children Denver II, Gesell figure and Block skill were chosen as the most representative measures.

Maternal data: A total of 5 female RAR with a mean age of 28.25 (range 28-31) years enrolled in this study. One female had hepatitis-C virus infection detected by ELISA and her HCV RNA load was 9,200,000 copies on polymerase chain reaction. Hence her pregnancy was terminated at 3 months. The original diseases for ESRD in the remaining 4 RAR were chronic glomerulonephritis in 2, benign decompensated nephrosclerosis in 1 and reflux nephropathy in 1 .
Three had live related donors and one had a deceased (cadaver) donor. Mean duration between RT and pregnancy was 38.25 (range 2648) months. Pre-pregnancy mean serum creatinine $(\mathrm{SCr})$ was 0.98 (range $0.8-1.1) \mathrm{mg} / \mathrm{dl}$. Pregnancy induced hypertension (PIH) was noted in 2, pre-eclampsia in 1 and jaundice with urinary tract infection (UTI) in 1 RAR. Three RAR were on dual immunosuppressive medications [1 on prednisolone $(\mathrm{P}), 10 \mathrm{mg} / \mathrm{day}$ and tacrolimus (T), $0.05 \mathrm{mg} / \mathrm{kg}$ body weight (BW) /day and 2 on P and azathioprine (A), 100 $\mathrm{mg} /$ day]. The fourth was on triple immunosuppression $\quad(\mathrm{P}+\mathrm{A}+\mathrm{T})$. Their hypertension was better controlled with continued sustained-release nifedipine and methyldopa anti-hypertensive medications.

Newborn data: Each RAR delivered a single baby. Two were full-term and 2 were preterm deliveries. Their mean gestational age was 35.25 weeks. Mean Apgar score was 8.25. One fullterm and 1 preterm newborn were small for gestational age (SGA). The other full-term and preterm newborn were adequate for gestational age (AGA). The mean birth weight was 2052.5 $\mathrm{g}$, the mean height $46.75 \mathrm{~cm}$, mean chest circumference $28.38 \mathrm{~cm}$ and mean head circumference $31 \mathrm{~cm}$ (table 1).

Table 1

Data on newborn of the 4 post renal allograft female recipients

\begin{tabular}{|c|c|c|c|c|}
\hline Characteristic & $1^{\text {st }}$ newborn & $2^{\text {nd }}$ newborn & $3^{\text {rd }}$ newborn & $4^{\text {th }}$ newborn \\
\hline Sex & $\mathrm{F}$ & $\mathrm{F}$ & $\mathrm{F}$ & $\mathrm{M}$ \\
\hline Gestational age (weeks) & 37 & 34 & 37 & 33 \\
\hline Birth weight (g) & 2600 & 1960 & 1800 & 1850 \\
\hline Height $(\mathrm{cm})$ & 50 & 49 & 44 & 44 \\
\hline Head circumference $(\mathrm{cm})$ & 33.5 & 31 & 29.5 & 30 \\
\hline Apgar score at birth & 9 & 8 & 8 & 8 \\
\hline Complication & Nil & icterus & Mild RDS & icterus \\
\hline Mode of delivery & LSCS & LSCS & LSCS & LSCS \\
\hline NICU care & Nil & Nil & 5 Days & Nil \\
\hline Current age (months) & 30 & 22 & 5 & 1.2 \\
\hline Current weight (g) & 11500 & 10000 & 5000 & 2500 \\
\hline Systolic BP (mmHg) & 84 & 72 & 62 & 55 \\
\hline Diastolic BP (mmHg) & 54 & 42 & 40 & 32 \\
\hline Physical examination & unremarkable & unremarkable & Squint (right eye) & unremarkable \\
\hline Congenital anomaly & Absent & Absent & Absent & Absent \\
\hline Ultrasound & Normal & Normal & Normal & Normal \\
\hline Serum creatinine $(\mathrm{mg} / \mathrm{dl})$ & 0.3 & 0.4 & 0.33 & 0.26 \\
\hline Urine albumin & Nil & Nil & Nil & Nil \\
\hline
\end{tabular}

RDS: respiratory distress syndrome, LSCS: lower segment caesarean section, NICU: neonatal intensive care unit; BP: blood pressure. 
One preterm-SGA newborn was admitted to the neonatal intensive care unit (NICU) for possibility of hypoglycaemia and icterus and was discharged on the $5^{\text {th }}$ day of life. This newborn required single surface phototherapy of 30 hours for physiological jaundice which developed on the $3^{\text {rd }}$ day of life. All other newborns were kept under observation in ward with mothers. Formula-feed was offered to all newborns. All passed urine in the first 6 hours and stool in the first 8 hours of life. All 3 were discharged on $3^{\text {rd }}$ postpartum day with their mothers. Two out of these 3 developed icterus neonatorum on $4^{\text {th }}$ and $5^{\text {th }}$ day of life noticed in well-baby clinic department, but did not require phototherapy. Their mean $\mathrm{SCr}$ was 0.32 (range: 0.26-0.4) $\mathrm{mg} / \mathrm{dl}$. None of them had congenital malformations or renal abnormalities on US. Neonatal reflexes were unremarkable in all.

\section{Follow-up examination}

One male and three females, ages ranging from 1 month and 5 days to 30 months, were studied at follow-up. The median age at time of assessment was 14.6 months with a mean weight of 7250 (range 2500-11,500)g. All were vaccinated according to their age. A comparison of babies born full term SGA and pre term SGA with full term and preterm AGA showed similar significant catch up growth. General health and physical assessment was unremarkable in all 4 children. Mean systolic and diastolic blood pressures (BP) were 68.25 (range 55-84) and 42 (range $32-54) \mathrm{mmHg}$ respectively. Urinalysis was unremarkable at follow-up. Two children had recurrent respiratory tract infection. Development was considered normal according to age (table 2).

Table 2: Developmental assessment of infants

\begin{tabular}{|c|c|c|c|c|}
\hline Test & $1^{\text {st }}$ newborn & $2^{\text {nd }}$ newborn & $3^{\text {rd }}$ newborn & $4^{\text {th }}$ newborn \\
\hline \multicolumn{5}{|l|}{ Denver II $^{2}$} \\
\hline Visual motor & Normal & Normal & Normal & Normal \\
\hline Language & Normal & Normal & Normal & Normal \\
\hline Motor & Advanced & Normal & Caution & Normal \\
\hline Behaviour & Normal & Normal & Normal & Normal \\
\hline Gesell figure $^{3}$ & $\begin{array}{c}\text { Differentiates horizontal } \\
\& \text { vertical lines }\end{array}$ & $\begin{array}{c}\text { Scribbles } \\
\text { spontaneously }\end{array}$ & Not able to perform & Not able to perform \\
\hline Block skill $^{4}$ & $\begin{array}{c}\text { Makes a train with } 4 \\
\text { blocks }\end{array}$ & $\begin{array}{l}\text { Makes } 4 \text { block } \\
\text { row }\end{array}$ & Not able to perform & Not able to perform \\
\hline $\begin{array}{l}\text { Primitive } \\
\text { reflexes }\end{array}$ & Absent & Absent & $\begin{array}{l}\text { ATNR,TLS, TLP, } \\
\text { palmar and plantar } \\
\text { grasp present }\end{array}$ & $\begin{array}{l}\text { MR, GR, ATNR, } \\
\text { palmar and plantar } \\
\text { grasp present }\end{array}$ \\
\hline
\end{tabular}

MR: Moro reflex, GR: Galant reflex, ATNR: asymmetric tonic neck reflex, TLS: tonic labyrinthine supine, $T L P$ : tonic labyrinthine prone

\section{Results}

Maternal data: All 4 RAR are alive and well with normal functioning grafts. In all 4 female RAR, allograft function remained normal throughout pregnancy and puerperium. All were delivered by lower segment caesarian section (LSCS), 3 for obstetrical reasons and 1 electively. Post-partum phase was uneventful in all with mean SCr of 1.1 (range: 0.9-1.3) $\mathrm{mg} / \mathrm{dl}$. Mean maternal $\mathrm{SCr}$ at conception in those infants born with intrauterine growth retardation (IUGR) $\left(\mathrm{BW}<10^{\text {th }}\right.$ centile for gestational age) $\mathrm{did}$ not differ significantly from those without IUGR. Complications during pregnancy resolved after delivery. Immunosuppression status was unchanged in all. Post-partum urine albumin was absent in all mothers and BP was controlled with the same anti-hypertensive medications.
Neonatal data: In this study, 50\% infants were born prematurely (before completion of 37 weeks of gestation), and $50 \%$ had IUGR. No one had any congenital malformations noted. Neonatal death was absent in the study. Granulocytopenia was not seen in any of the children.

\section{Discussion}

Delivery of a normal child is possible in a RAR provided careful planning and monitoring of pregnancy is accomplished. The time interval between transplantation and conception should be $\geq 2$ years of normal stable graft function $(\mathrm{SCr}<1.4 \mathrm{mg} / \mathrm{dl})$, there should be absent or satisfactorily controlled hypertension, absent or minimal proteinuria and minimal 
immunosuppression with no evidence of active graft rejection or pelvicalyceal distension ${ }^{5}$.

The neonatal outcomes were generally good in our study group despite $50 \%$ incidence of risk factors such as prematurity and IUGR. In view of the prevalence of IUGR and preterm delivery, neonatal problems such as hypoglycaemia, icterus neonatorum and RDS are predictable. There were no RDS created problems in our study group possibly due to use of maternal corticosteroids prior to delivery

Maternal immunosuppression is of critical importance in maintaining stable renal allograft function without any adverse influence on the developing embryo and fetus. Prednisolone has been shown to cause preterm birth in animal models ${ }^{6}$. Neonatal adrenal insufficiency has been described in human infants of transplanted mothers exposed to corticosteroids ${ }^{7,8,9}$ and azathioprine has been associated with skeletal and central nervous system anomalies in animals $^{10,11}$.

There is a risk of complications for both the fetus and mother with $25 \%$ chances of spontaneous abortion and $50-66 \%$ chances of IUGR and/or premature delivery ${ }^{12}$. Abortions were noted in two RAR in our study, one of whom had 2 abortions in the first trimester within one year of RT. She was advised to conceive after a total duration of 2 years of RT. Aramenti et al have reported that transplant interval of shorter duration $(<1-2$ years) was associated with greater risk of unsatisfactory outcome, and that longer interval ( $>5$ years) after transplantation was associated with lower incidence of prematurity and low birth weight. Thus, women should be advised to use optimal contraception in the first 2 years after $\mathrm{RT}^{13}$.

No pattern of fetal anomalies has emerged with maternal corticosteroids, azathioprine, tacrolimus or cyclosporine in either animal model or in humans, though LBW and premature deliveries are associated with immunosuppressive agents ${ }^{6,14,15,16}$. Fortunately we did not encounter any anomalies in our study group. The children in our study, while tending to be premature and small, have shown very impressive catch-up growth. As far as we know, this has not been previously reported. This suggests that postnatal progress is not adversely influenced by maternal immunosuppression or renal function.
Little data is available on breast-feeding by mothers taking immunosuppressive medication. The American Association of Paediatrics supports breast-feeding by mothers taking prednisolone, advises against breast-feeding by those taking cyclosporine, and provides no recommendations regarding azathioprine or tacrolimus. Whether the risk of exposure to immunosuppression through breast milk outweighs the benefits of breast-feeding, remain unknown ${ }^{17}$.

Child development and general health were normal in our study group. Developmental delay reported in other studies may be due to perinatal asphyxia rather than being related to the maternal renal allograft or immunosuppression.

There are numerous psychological issues arising in families of a female RAR. These include maternal anxiety regarding her own health as well as of her children. Almost all mothers in our study were apprehensive initially about the possibility of renal disease in their children, often without raising the issue with their paediatrician. There is a paucity of literature concerning psychological development within these families although one study suggests that most children develop without behavioural problems and that most parents are 'well adjusted', though having a low threshold for seeking medical attention for their children ${ }^{18}$.

BP was normal in all children, though there is some support for the suggestion put forward by Barker and others, of birth weight being inversely related to subsequent $\mathrm{BP}^{19,20}$.

One purpose of our study was to consider the renal outcome of all children of RAR. Children underwent haematological, urinalysis, $\mathrm{SCr}$ and radiology investigations to rule out granulocytopenia, abnormal renal function and congenital anomaly. US although relatively crude screen with regards to vesico-ureteric reflux. Renal tract abnormality was absent in our study.

In our RT population, patients' own wish to become a mother and conceive a baby was decisive. Social factors had no marked influence on patient's decisions for pregnancy in our study.

In developing countries, regretfully many of these pregnancies are not planned, the allograft recipient being unaware that they could conceive 
and therefore they take prenatal care quite late in gestation. Patients therefore must be referred to highly specialized centres where obstetricians, nephrologists, intensivists, and neonatologists provide surveillance and treatment ${ }^{21}$.

\section{Conclusions}

- Childbirth in renal allograft recipients (RAR) with stable graft function improves social quality of life of families.

- Post-natal progress is not adversely influenced by immunosuppression of RAR.

- Preterm-delivery and intrauterine growth retardation remain risk factors.

This small report is likely to stimulate our colleagues in developing countries, who are still uncertain about the pregnancies in female RAR, and help them to revise their views. It seems prudent on the part of treating physicians to discuss the possibility of having a baby with their patients in appropriate clinical circumstances.

\section{Acknowledgments}

The authors thank our librarian J Suthar for literature search and manuscript preparation. We also thank the Radiology Department for carrying out the ultrasound examinations of the children.

\section{References}

1. Murray JE, Ried DE, Harrison JH, et al. Successful pregnancies after human renal transplantation. New England Journal of Medicine 1963; 269:341-3. http://dx.doi.org/10.1056/NEJM1963081526 90704

2. Frankenberg WE, Dodds JB. The Denver Development Assessment (Denver II) Denver: University of Colorado Medical School; 1990.

3. IIIingworth RS. The development of the infant and young child, normal and abnormal, $5^{\text {th }}$ ed. Baltimore: Williams and Wilkins; 1972.
4. Capute AJ Accardo PJ. The paediatrician and the developmentally disabled child: a clinical text book on mental retardation. Baltimore: University Press; 1979.

5. M Ahmad. Outcome of pregnancies in renal allograft recipients. Journal of the Association of Physicians of India 2003; 51: 208-10.

6. Simon NG, Karow WG, Gandelman R. Prenatal exposure to prednisone in humans and animals retards intrauterine growth. Science 1978; 202(4366):436-8. http://dx.doi.org/10.1126/science.705336

7. Penn I, Makowski E, Droegemuller W, Halgrimson CG, Starzl TE. Parenthood in renal homograft recipients. Journal of the American Medical Association 1971; 216(11):1755-61. http://dx.doi.org/10.1001/jama.216.11.1755

8. Divison JM, Lind T, Uldall PR. Planned pregnancy in a renal transplant recipient. Journal of Obstetrics and Gynecology 1976; 83(7):518-27.

http://dx.doi.org/10.1111/j.14710528.1976.t b00879.x

9. Lower GD, Stevens LE, Najarian JS, Reemtsma K. Problem from immunosuppressives during pregnancy. American Journal of Obstetrics and Gynecology 1971; 111(8):1120-1.

10. Githens JH, Rozenkrantz JG, Tunnock SM. Teratogenic effect of azathioprine. Journal of Pediatrics 1965; 66:959-61 http://dx.doi.org/10.1016/S00223476(65)80 071-3

11. Rozenkrantz JG, Githens JH, Cox SM, Kellum DL. Azathioprine (Imuran) and pregnancy. American Journal of Obstetrics and Gynecology 1967; 97(3):387-94

12. Nicovani V, Poblete H, Toro J, Carrera M, Perez L. Successful multiple pregnancy (triplets) in a kidney transplant recipient: A case report. Transplantation Proceedings 2009; 41(6):2688-90. http://dx.doi.org/10.1016/j.transproceed.200 9.06.129 
13. Armenti VT, Ahlswede BA, Moritz MJ, Jarrell BE. National Transplantation Pregnancy Registry: Analysis of pregnancy outcomes of female kidney recipients with relation to time interval from transplant to conception. Transplantation Proceedings 1993; 25(1 Pt. 2):1036-7.

14. Blowey DL, Warady BA. Neonatal outcome in pregnancies associated with renal replacement therapy. Advances in Renal Replacement Therapy 1998, 5(1):45-52.

15. Hou S. Pregnancy in chronic renal insufficiency and end stage renal disease. American Journal of Kidney Diseases 1999; 33(2):235-52.

http://dx.doi.org/10.1016/S02726386(99)70 296-9

16. Mason RJ, Thomson AW, Whiting PH et al. Cyclosporin-induced feto-toxicity in the rat. Transplantation 1985; 39(1):9-12.

17. McKay DB, Michelle A. Josephson MA. Pregnancy in recipients of solid organs: Effects on mother and child. New England Journal of Medicine 2006; 354(12):1281-93. http://dx.doi.org/10.1056/NEJMra050431
18. Korsh BM, Klein JD, Negrete VF, Henderson DJ, Fine RN. Physical and psychological follow-up on offspring of renal allograft recipients. Pediatrics 1980; 65(2):275-83.

19. Barker DJP, Bull AR, Osmond G, Simmonds SJ. Fetal and placental size and risk of hypertension in adult life. British Medical Journal 1990; 301(6746):259-62.

http://dx.doi.org/10.1136/bmj.301.6746.259

20. Martyn CN, Barker DJP, Jesperson S et al. Growth in utero, adult blood pressure, and arterial compliance. British Heart Journal 1995; 73(2):116-21.

http://dx.doi.org/10.1136/hrt.73.2.116

21. Di Loreto P, Martino F, Chiaramonte S: Pregnancy after kidney transplantation: two transplantation centres-Vicenza-Udine experience. Transplantation Proceedings 2010; 42(4):1158-61.

http://dx.doi.org/10.1016/j.transproceed.201 0.03 .082 